\title{
CALCIFIED RIGHT-ATRIAL WALL THROMBUS IN A PATIENT OF RHEUMATIC VALVULAR HEART DISEASE- A RARE ASSOCIATION
}

\author{
Sunil Dhar1, Amit Agarwal2, Ajit Kumar Padhy33, Anubhav Gupta ${ }^{4}$
}

${ }^{1}$ Senior Resident, Department of Cardiothoracic and Vascular Surgery, Vardhman Mahavir Medical College and Hospital, Safdarjung, New Delhi, India.

2Senior Resident, Department of Cardiothoracic and Vascular Surgery, Vardhman Mahavir Medical College and Hospital, Safdarjung, New Delhi, India.

${ }^{3}$ Assistant Professor, Department of Cardiothoracic and Vascular Surgery, Vardhman Mahavir Medical College and Hospital, Safdarjung, New Delhi, India.

${ }^{4}$ Professor, Department of Cardiothoracic and Vascular Surgery, Vardhman Mahavir Medical College and Hospital, Safdarjung, New Delhi, India.

HOW TO CITE THIS ARTICLE: Dhar S, Agarwal A, Padhy AK, et al. Calcified right- atrial wall thrombus in a patient of rheumatic valvular heart disease- a rare association. J. Evolution Med. Dent. Sci. 2019;8(11):824-825, DOI: 10.14260/jemds/2019/183

\section{PRESENTATION OF CASE}

Calcified right atrial wall thrombus (RAWT) is a rare entity and is usually associated with intra cardiac catheters, malignancy and hypercoagulable states. We report a case of 20-year-old female who had rheumatic valvular heart disease detected to have calcified RAWT incidentally during routine intraoperative transoesophageal echocardiography (TEE). A 20 -year- old female was admitted with diagnosis of chronic rheumatic heart disease with severe mitral regurgitation, moderate aortic regurgitation and severe tricuspid stenosis. Left atrium was aneurysmal. (LAES $84 \mathrm{~mm}$ ).

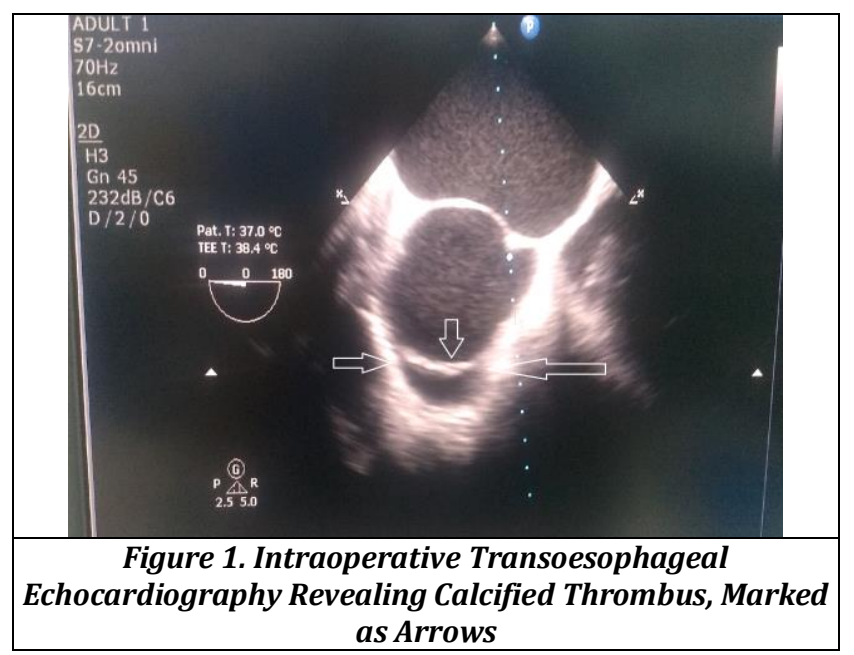

\section{DISCUSSION OF MANAGEMENT}

Patient underwent double valve replacement (mitral valve replacement with $27 \mathrm{~mm}$ ST. Judes mechanical valve and 19 mm ST. Judes Regent series aortic valve) with total chordal preservation, left atrial reduction plasty and tricuspid commissurotomy. Intra operative TEE revealed presence of right atrial mass (Figure 1).

\footnotetext{
'Financial or Other Competing Interest': None.

Submission 29-01-2019, Peer Review 05-03-2019,

Acceptance 11-03-2019, Published 18-03-2019.

Corresponding Author:

Dr. Sunil Dhar,

C-133, Jalvayu Vihar,

Gurgaon-122001, Haryana, India.

E-mail:drsunil09@gmail.com

DOI: $10.14260 /$ jemds/2019/183

(c) $(1) \ominus$
}

Intraoperatively, multiple calcified thrombi were seen adherent to the trabeculated portion of the right atrial wall (Figure 2). Thrombi were extracted from right atrium. The post-operative phase was uneventful and discharged on seventh postoperative day.

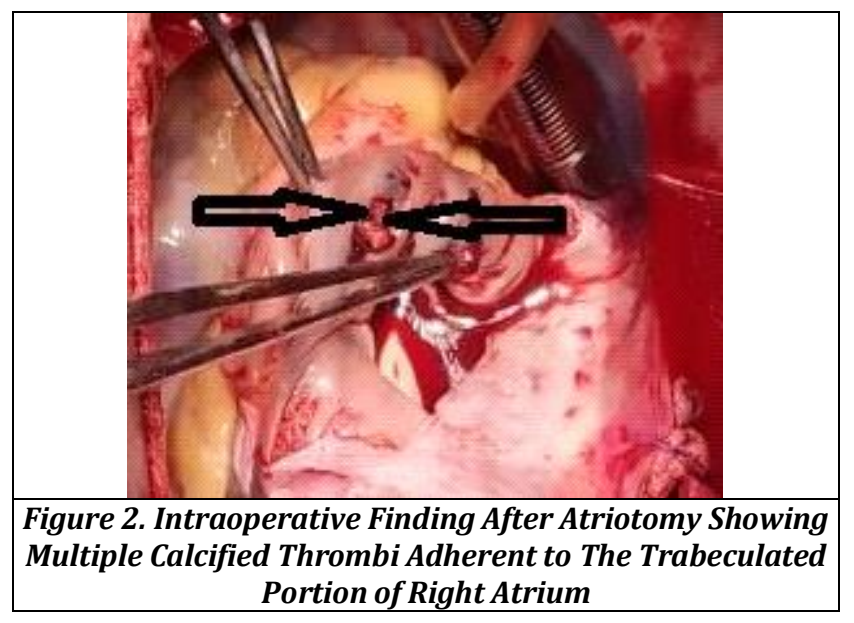

RAWT is very rare; moreover, RAWT has not been reported in rheumatic heart disease to the best of our knowledge. The reported incidence of right atrial thrombus is around $12.5 \%$ in literature, RAWT is the rarest form of right atrial thrombus. Thrombus is generally associated with the in-situ catheter tip, malignancy, infection, procoagulant states and structural abnormalities. ${ }^{1}$

Incidence of right atrial thrombus in appendage in atrial fibrillation is 3 to $6 \%$, while in left atrium it is $13 \%$.It is ascribed to the fact that the right atrial appendage, being considerably shallower than the left, provides a less hospitable environment for thrombus formation. . $, 3,4^{2}$

Right atrial thrombus is classified on the basis of morphology as 5 -

Type A: Thrombi are morphologically serpiginous, highly mobile, may prolapse through the tricuspid valve and are associated with deep vein thrombosis and pulmonary embolism.

Type B: Thrombi- are less mobile, attached to the right atrial or ventricular wall and originate in association with foreign bodies or in structurally abnormal chambers. 
Type C: Thrombi are rare, share and similar appearance to a myxoma and are highly mobile.

Patients with suspicion of RA thrombus should be subjected to TEE as it is a better modality compared to standard TTE. Detection is also determined by size, mobility, and site of attachment. 6

TEE plays an important role in the evaluation of right atrial wall thrombus. Incidence of right atrial wall thrombus in rheumatic valvular disease is rare. Patients with atrial fibrillation should be evaluated by intraoperative TEE. The exact mechanism of development of right atrial wall thrombus may be related to the relative stasis of blood in atrial fibrillation.

\section{REFERENCES}

[1] Gilon D, Schechter D, Rein AJ, et al. Right atrial thrombi are related to indwelling central venous catheter position: Insights into time course and possible mechanism of formation. Am Heart J 1998;135(3):457-62.
[2] Torbicki A, Galiè N, Covezzoli A, et al. Right heart thrombi in pulmonary embolism: results from the International Cooperative Pulmonary Embolism Registry. J Am Coll Cardiol 2003;41(12):2245-51.

[3] Bashir M, Asher CR, Garcia MJ, et al. Right atrial spontaneous echo contrast and thrombi in atrial fibrillation: a transesophageal echocardiography study. J Am Soc Echocardiogr 2001;14(2):122-7.

[4] Ogren M, Bergqvist D, Eriksson H, et al. Prevalence and risk of pulmonary embolism in patients with intracardiac thrombosis: a population-based study of 23796 consecutive autopsies. Eur Heart J 2005;26(11):1108-14.

[5] Onwuanyi AE, Brown RJ, Vahedi M, et al. Eustachian valve thrombus: Critical factor in outcome of venous thromboembolism. Echocardiography 2003;20:71-3.

[6] Obeid AI, Mudamgha A, Smulyan H. Diagnosis of right atrial mass lesions by transesophageal and transthoracic echocardiography. Chest 1993; 103(5): 1447-51. 